\title{
Gestão do conhecimento: avaliação de práticas aplicadas em uma cooperativa de crédito e investimento
}

\section{Knowledge management: evaluation of practices applied in a credit and investment cooperative}

\author{
Sandra Martins Moreira \\ Universidade Tecnológica Federal do Paraná - UTFPR - Ponta Grossa - Brasil \\ sandrammoreira77@gmail.com \\ Patricia Koch \\ União de Ensino do Sudoeste do Paraná - UNISEP - Dois Vizinhos - Brasil \\ paty16koch@hotmail.com \\ Diego Zanatta Maria \\ União de Ensino do Sudoeste do Paraná - UNISEP - Dois Vizinhos - Brasil \\ diego@unisep.edu.br \\ Antonio Carlos de Francisco \\ Universidade Tecnológica Federal do Paraná - UTFPR - Ponta Grossa - Brasil \\ acfrancisco@utfpr.edu.br
}

\section{Resumo}

O presente artigo tem como objetivo avaliar as práticas do espiral do conhecimento aplicadas em uma cooperativa de crédito e investimento do sudoeste do Paraná, mostrando a percepção de seus colaboradores em relação a essas práticas. $\mathrm{O}$ artigo buscou enumerar as práticas que a cooperativa desenvolve com seus colaboradores, em seguida aplicado o espiral do conhecimento para classificar essas práticas, e por fim, verificado qual a percepção dos colaboradores em relação a essas práticas. Para o desenvolvimento do tema foi utilizado o estudo de caso para mensurar as práticas de gestão do conhecimento da cooperativa Sicredi Iguaçú PR/SC/SP. O resultado foi dividido em duas partes: primeiro a identificação das práticas de gestão do conhecimento através de pesquisa exploratória e entrevista com o setor de recursos humanos e sociais da cooperativa e em um segundo momento foi desenvolvido dois instrumentos para os colaboradores, e assim destacar a visão e importância dos mesmos em relação a forma de gestão do conhecimento que a Sicredi Iguaçú PR/SC/SP gerencia. Com a pesquisa obteve-se o resultado de que a cooperativa desenvolve 11 práticas de gestão do conhecimento com os seus colaboradores e que todos têm acesso a essas práticas, algumas precisam de investimento para serem desenvolvidas e outras apenas de incentivo e alguns materiais impressos ou online, e de modo geral os colaboradores consideram as práticas desenvolvidas muito importante para o seu crescimento profissional.

Palavras-chave: gestão do conhecimento, práticas de gestão, aprendizagem.

\section{Abstract}


This article deals with the evaluation of practices applied in a cooperative financial institution with headquarters in the southwestern region of Paraná. The article aimed to enumerate the practices that the cooperative develops with its employees, then applied the knowledge spiral to classify these practices, and finally, verified the employees' perception of these practices. For the development of the theme, a case study was used to measure the knowledge management practices of the Sicredi Iguaçú PR / SC / SP cooperative. The result was divided into two parts: first, knowledge management practices were identified through exploratory research and interviews with the cooperative's human and social resources sector, and secondly, two instruments were developed for the employees, thus highlighting the vision and their importance in relation to the form of knowledge management that Sicredi Iguaçú PR / SC / SP manages. With the research the result was that the cooperative develops 11 knowledge management practices with its employees and that all have access to these practices, some need investment to be developed and others only incentive and some printed materials or online, and in general the employees consider the developed practices very important for their professional growth.

Keywords: knowledge management, management practices, learning.

\section{Introdução}

A busca constante das organizações em se manterem em alta no mercado, gerar cada vez mais resultados, inovar seus produtos e serviços e ainda acompanhar os avanços tecnológicos, mostrou muitas oportunidades dentro das organizações e na economia mundial, mas que para a oportunidade não seja perdida e acabe a empresa por ter de fechar as porta, a empresa precisa se destacar dentre as outras do mesmo ramo, por meio de um diferencial competitivo (BEHR; NASCIMENTO, 2008).

Conscientes da importância em investir em mudanças dentro das organizações, as mesmas começaram a estudar o seu capital humano, Fialho e Ponchirolli (2005) discorrem que se faz necessário um estudo sobre como esta sendo gerenciado o conhecimento produzido dentro das organizações, pois com essa ferramenta as empresas conseguem ter um diferencial competitivo usando o conhecimento á seu favor.

Segundo Nonaka e Takeuchi (1997, p. 33) "a criação do conhecimento indica a sabedoria adquirida a partir da perspectiva da personalidade do grupo, e para que seja bem aproveitado é essencial que haja um gerenciamento do conhecimento".

Hoje na era do conhecimento e informação, a gestão do conhecimento é essencial para o sucesso da instituição. Davenport e Prusak (2003) ao discutirem sobre a importância de se investir em conhecimento argumentam que o conhecimento é sustentável, pois o valor dos produtos e serviços quase sempre conseguem ser igualados pelos oponentes, porém a criatividade, qualidade e eficiência de uma empresa repleta de conhecimento e que administra esse capital intelectual dificilmente será atingida.

No processo de geração do conhecimento acontece à troca de dados, ideias, experiências e informações dentro e fora da organização, essa permuta resulta em um espiral do conhecimento que ocorre por meio de quatro conversões: socialização, externalização, combinação e internalização (NONAKA; TAKEUCHI, 1997). Dentro dessas etapas está o conhecimento tácito e explícito.

Tem-se como objetivo avaliar as práticas do espiral do conhecimento aplicadas em uma cooperativa de crédito e investimento do sudoeste do Paraná, mostrando a percepção de seus colaboradores em relação a essas práticas.

\section{Referencial Teórico}


Nos anos 1990 por meio das publicações dos escritores Nonaka e Takeuchi (1997) e Davenport Prusak (2003), surge o termo gestão do conhecimento (GC), eles mostraram em seus livros a importância do conhecimento para as empresas e como fazer para gerenciar o conhecimento, e assim obter vantagem competitiva em meio ao mercado (PEREIRA, 2015).

Nesse sentido, Behr e Nascimento (2008) comentam que o início da GC deu-se pela demissão de colaboradores altamente especializados e a redução do quadro de empregados nas empresas americanas e européias, devido ao repentino avanço tecnológico da comunicação e informação.

De acordo com Terra (2000 apud BEAL; CARLETTO; FERREIRA, 2008) comentam que para melhor compreensão do valor de se gerenciar o conhecimento é preciso conhecer suas dimensões.

Quadro 1: Dimensões da gestão do conhecimento

\begin{tabular}{|l|l|}
\hline \multicolumn{1}{|c|}{ Fatores } & \multicolumn{1}{c|}{ Descrição } \\
\hline $\begin{array}{l}\text { Função da alta administração e } \\
\text { fatores estratégicos }\end{array}$ & $\begin{array}{l}\text { Tem papel fundamental para o desenvolvimento de } \\
\text { metas e objetivos da organização. }\end{array}$ \\
\hline Cultura e valores & $\begin{array}{l}\text { E necessário desenvolver uma cultura forte, a qual } \\
\text { presa pela inovação, desenvolvimento de seus } \\
\text { colaboradores, objetivos de longo prazo, otimização de } \\
\text { toda a empresa. }\end{array}$ \\
\hline Hierarquia organizacional & $\begin{array}{l}\text { A estrutura da empresa deve ter certa autonomia, ter } \\
\text { equipe multidisciplinares. }\end{array}$ \\
\hline Recursos humanos & $\begin{array}{l}\text { Aperfeiçoamento constante dos meios e formas e } \\
\text { atração, contratação, retenção de profissionais. }\end{array}$ \\
\hline Sistema de informação & $\begin{array}{l}\text { Em um ambiente com confiança e transparência, seu } \\
\text { objetivo é a obtenção e armazenamento do } \\
\text { conhecimento. }\end{array}$ \\
\hline Mensuração dos resultados & $\begin{array}{l}\text { Avaliação de várias dimensões do capital intelectual da } \\
\text { organização. }\end{array}$ \\
\hline Aprendizado com o ambiente & $\begin{array}{l}\text { Relações com outras organizações e melhor } \\
\text { relacionamento com os clientes. }\end{array}$ \\
\hline
\end{tabular}

Fonte: Adaptado de Beal, Carletto e Ferreira (2008)

$\mathrm{Na}$ sua essência, a GC agrega valor às informações, dados e novas ideias, identificando, arquivando e compartilhando esse conhecimento com todos os interessados, concedendo assim, mais importância ao capital humano das organizações. No entanto, é fundamental o ambiente de trabalho estar propício ao compartilhamento do conhecimento, incentivando as pessoas a compartilharem o que aprenderam, mas também salienta que essa tarefa não é fácil (INAZAWA, 2009).

Inazawa (2009) vai além e salienta que, "a gestão do conhecimento tem encontrado resistências" Inazawa (2009, p. 209), pois muitas empresas não querem dar aberturar para os colaboradores aprenderem sobre sua organização e seu modelo de gestão.

Para Souza (2003, p. 232) "a GC deve ser considerado um diferencial competitivo", por fornecer à empresa uma melhora na comunicação interna e externa, conseguir gerenciar o que cada um sabe e aprende no ambiente de trabalho e ainda explorar melhor seus recursos. Em termos práticos, a GC é um ativo valioso e sustentável dentro das organizações.

\subsection{Tipos de conhecimento}

Segundo Terra e Kruglianskas (2003), a gestão do conhecimento é a prática de gerar, armazenar e multiplicar o conhecimento que está sendo produzido na empresa.

Dentro da gestão do conhecimento há uma separação entre o que está 
escrito/registrado em manuais, em treinamentos formais e metódicos, normas e políticas internas e em banco de dados, em relação ao conhecimento que foi adquirido pelas pessoas ao longo dos anos, suas experiências, habilidades, desta forma é mais difícil de ser compartilhado com os demais. Nonaka e Takeuchi (1997) definem esses dois tipos de conhecimento explícito e tácito respectivamente.

Quando ocorre a permuta entre o tácito e explícito, isto é, entre o conhecimento que esta dentro das pessoas e o externo, formal e documentado, formam um ciclo conhecido como espiral do conhecimento, composto por quatro etapas que são: a socialização, externalização, combinação e a internalização, essas categorias são definidas por Terra e Kruglianskas (2003) como:

a) Socialização: troca de experiências e conhecimento entre os indivíduos, aprendizado na prática, interação face a face, nessa fase o conhecimento tácito de transforma em um novo conhecimento tácito;

b) Externalização: nesta fase o tácito se transforma em um novo explícito, nesse contexto, ocorre o registro do conhecimento em documentos, planilhas, manuais, modelos;

c) Combinação: é a junção de um conhecimento explícito com outro explícito, gerando um novo conhecimento explícito. Um exemplo seria os bancos de dados, análise de dados e informações.

d) Internalização: nessa fase o conhecimento explícito gera um conhecimento tácito, ou seja, o conhecimento lido é absorvido, aprendizado em prática, outro exemplo seria a realização de simulados e testes.

Figura 1: Espiral conhecimento, conversão entre tácito e explícito

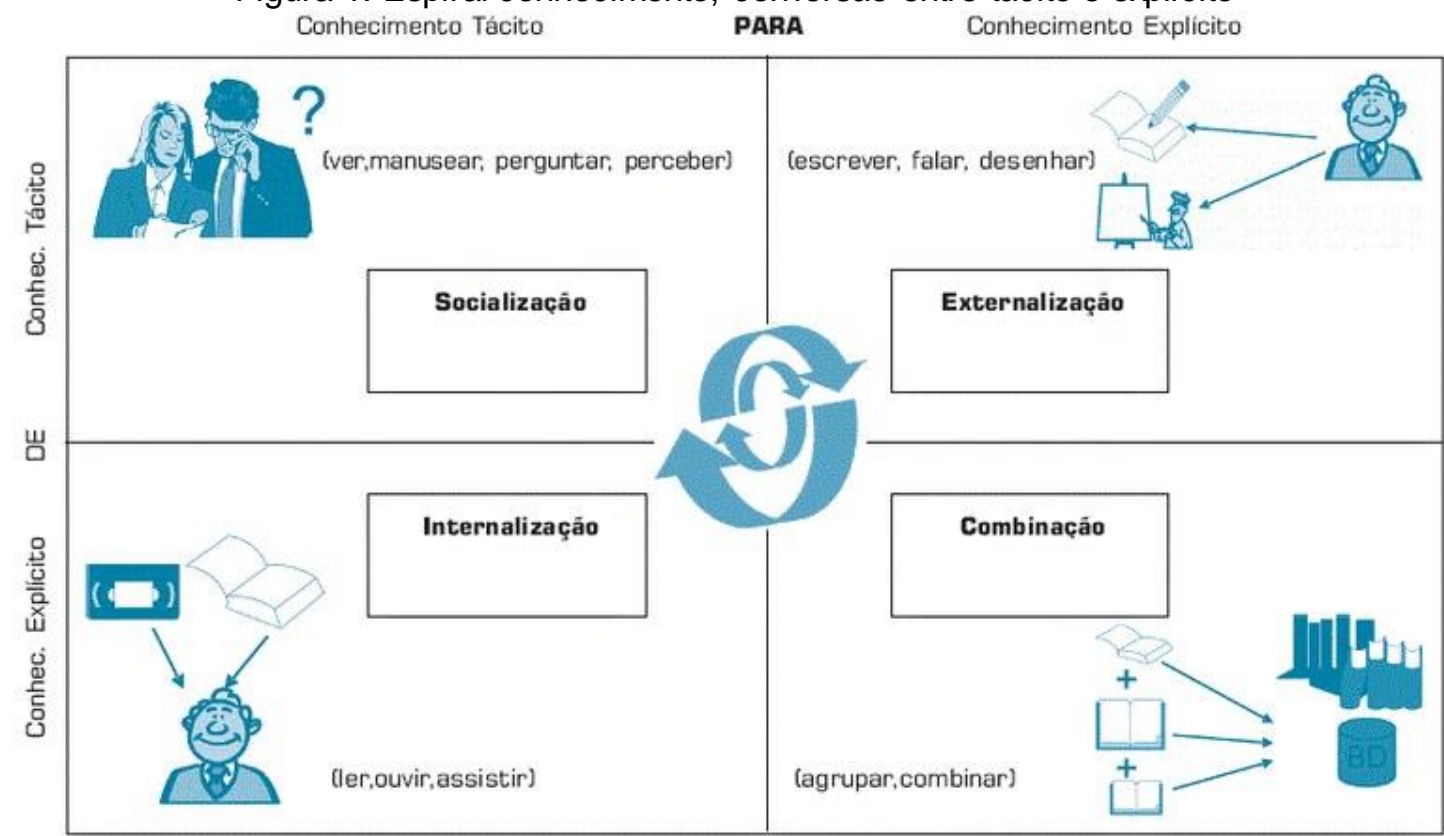

Fonte: Silva e Rozenfeld (2003, p.14); Nonaka e Takeuchi(1997)

No processo de construção do conhecimento organizacional, de acordo com Drucker (2004, apud MONTANARI, 2009), a empresa pode se beneficiar do recurso do conhecimento aplicado no trabalho pelos seus colaborares, a empresa pode despertar o interesse no compartilhamento do conhecimento através de projetos organizacionais que envolvem a troca de ideias entre todos os níveis hierárquicos, transformando o conhecimento de um individuo em um conhecimento coletivo.

De acordo com Pereira (2015 apud BATISTA, 2004),) existem várias propostas de práticas de gestão do conhecimento que podem ser encontradas na literatura, sendo que gestão do conhecimento nada mais é do que as práticas de gestão organizacional. No 
entendimento de Pereira (2015), a organização pode planejar suas ações, fazer a retenção do conhecimento, compartilhar com os demais e aplicar o conhecimento para que a empresa alcance seus objetivos através de seu pleno funcionamento.

\section{Metodologia}

Este artigo classifica-se de acordo com Gil (2009) quanto aos objetivos como pesquisa descritiva com abordagem qualitativa, em relação aos procedimentos como pesquisa documental e estudo de caso. Já para responder ao problema foi adotado o método de procedimento de pesquisa estudo de caso, o qual visa verificar as práticas empregadas na empresa.

Em termos práticos, a pesquisa seguiu os procedimentos prescritos por Yin (2001) observando as seguintes etapas: a) revisão bibliográfica; b) definição da população; c) coleta de dados e informações; d) análise do espiral do conhecimento com os dados e informações coletadas; e) elaboração de questionário para verificar a percepção dos colaboradores em relação as práticas utilizadas pela cooperativa; f) aplicação do questionário; g) análise dos dados e resultados.

A cooperativa de crédito do presente estudo faz parte da instituição financeira cooperativa Sicredi, a qual atua em 21 Estados do Brasil. A agência cooperativa escolhida para serem aplicados os questionários atua na cidade de Dois Vizinhos e pertence à Cooperativa Sicredi Iguaçú PR/SC/SP.

A coleta de dados deu-se em duas etapas, primeiro foram realizadas pesquisas no site da cooperativa, análise de documentos e entrevista com o setor de recursos humanos, a qual foi desenvolvida com base na fundamentação teórica do estudo, com o intuito de identificar quais práticas de gestão do conhecimento que a cooperativa desempenha. Essas pesquisas foram realizadas nos meses de novembro e dezembro de 2017.

No segundo momento foram desenvolvidos questionários pela própria autora para verificar a percepção dos colaboradores em relação às práticas de gestão do conhecimento realizadas na cooperativa. Esses questionários foram aplicados na agência durante o mês de janeiro de 2018. O universo pesquisado foi uma população de uma 11 colaboradores, assim $100 \%$ dos empregados da agência responderam aos questionários.

\section{Resultados e Discussões}

\subsection{Práticas de Gestão do Conhecimento}

A cooperativa Sicredi Iguaçú PR/SC/SP desenvolve práticas de gestão do conhecimento e tem como estratégia realizar melhorias anualmente, inovando e investimento cada vez mais no conhecimento de seus colaboradores. Além das práticas citadas na sequência existem outras desenvolvidas para a comunidade e a seus associados, porém isso não fez parte do objetivo do trabalho, por isso elas não foram apresentadas.

Descrevem-se no primeiro momento da pesquisa as práticas de gestão do conhecimento aplicadas pela cooperativa.

a) Reuniões internas: são realizadas reuniões internas entre os setores de área de negócios e o administrativo, com objetivo de repassar informações de cada setor mantendo a comunicação entre os colaboradores fazendo com que a agência esteja engajada com os seus objetivos.A Cooperativa também realiza reuniões durante o ano com todos os Gerentes de Agência e com os Gerentes Administrativos Financeiro, que acontecem na Sede da Cooperativa e com o apoio e organização da Superintendência Regional. Essas reuniões visam fazer 
alinhamentos de estratégicas de vendas e alcance das metas entre os colaboradores, repassar informações importantes, elaborar o planejamento, entre outras. Em 2017 também foi implantado o sistema de Videoconferência na Sede da Cooperativa, que possibilita a realização de reuniões mais rápidas e sem precisar do deslocamento de colaboradores;

b) Mensuração dos resultados: a Superintendência Regional realiza com cada agência uma reunião para explicar como foi o desenvolvimento da cooperativa em geral e como foi o desempenho da agência naquele ano calendário. Assim todos os colaboradores estarão envolvidos e cientes dos resultados e metas alcançadas;

c) Estatuto social: é um conjunto de normas e regras internas que orientam os colaboradores e associados quanto aos atos, funções e objetivos da cooperativa. Esse estatuto é entregue para cada novo colaborador;

d) Treinamentos/capacitações: os treinamentos são coletivos, porém separados para cada setor ou de acordo com a função de cada colaborador. A cooperativa investe em cursos, conferências, treinamentos para os seus colaborares, gerentes e diretores durante 0 ano. Alguns treinamentos são proporcionados/contratados pela Superintendência Regional e outros são proporcionados pela Central Sicredi PR/SP/RJ, sendo que esses geralmente são realizados em Curitiba. Também são realizados os treinamentos na função, os quais ocorrem quando um novo colaborador entra na agência ou então quando é remanejado de função, o treinamento varia de acordo com cada função, mas em média acontece durante uma semana sobre a supervisão de um colega, o qual vai passando todas as orientações e suas experiências sobre aquela função;

e) Cursos e palestras: a cooperativa tem um site de acesso individual (Sicredi Aprende), onde logo que um novo colaborador inicia suas atividades já estão disponíveis cursos online obrigatórios de acordo com a sua função e ao longo do ano são disponibilizados novos cursos de aprimoramento e novos conhecimentos. Caso o colaborador queira aprender algo que não seja da sua área de atuação basta ele fazer sua inscrição e realizar o curso. O Sicredi Iguaçú PR/SC/SP também realiza cursos e palestras presenciais com temas abrangentes ao mercado;

f) Integração de novos colaboradores: a integração é realizada na Superintendência Regional com todos os novos colaboradores de todas as agências, essa prática é conhecida como ambientação, e costuma ser realizada uma vez ao mês. Durante esse dia de ambientação, os novos colaboradores conhecem os setores, colegas e a estrutura da Superintendência Regional, são repassadas informações sobre o Cooperativismo e o Cooperativismo de Crédito, o Sistema Sicredi, relativo à cooperativa, regras, políticas existentes, ética profissional, vídeos institucionais e informativos, explicado sobre o estatuto social, os projetos e programas sociais que a cooperativa desenvolve;

g) Auxílio educação: a cooperativa incentiva seus colaboradores ao estudo com o objetivo de ampliar os conhecimentos e a cultura geral quanto a processos, métodos e técnicas utilizadas no mercado. Este auxílio visa auxiliar e incentivar os colaboradores na realização de cursos de pós-graduação, mestrados e doutorados e cursos de idiomas voltados para a área em que trabalham. Diante disso, o colaborador que atende todos os pré-requisitos necessários, que fez sua solicitação e for aprovada, terá $50 \%$ do valor das mensalidades e matrícula dos cursos pagos pelo Sicredi;

h) Biblioteca interna: o Sistema Sicredi possui a Biblioteca Sicredi, localizada no Centro Administrativo do Sicredi em Porto Alegre-RS, onde disponibiliza aos 
seus colaboradores e associados um grande acervo de livros, revistas e trabalhos de conclusão de curso. Os mesmos estão disponíveis para reserva em um site e entregues via malote na agência que realizou a solicitação. A Biblioteca auxilia as agências, Superintendências Regionais e Centrais na seleção de materiais de informação, promove a dinamização das coleções, auxilia os usuários na busca por informação, fomenta a literatura cooperativista e promove a leitura como meio de valorização e desenvolvimento das pessoas;

i) Portal corporativo: chamado de Rede Colaborativa proporciona a todos os colaboradores um canal de comunicação do Sistema Sicredi, com notícias, informativos, portais de acesso a todas as áreas do Sicredi, suporte ao colaborador, gestão de pessoas, compliance, permite o acompanhamento de seu desempenho, entre outros. Além disso, traz todas as informações sobre o Sicredi, seus números, programas sociais, ferramentas etc;

j) Comunicação/e-mails/murais: para a disseminação de conhecimento e rápida comunição entre à cooperativa e seus colaboradores e entre eles, são utilizados diversos meios de divulgação, os mais utilizados são os e-mails, murais e grupos de WhatsApp;

k) Programa crescer: programa desenvolvido pela cooperativa com o objetivo de aproximar os associados da sua Cooperativa, fazendo com que eles conheçam mais sobre as vantagens do cooperativismo de crédito e seu funcionamento. $O$ programa visa fortalecer a cultura do Cooperativismo de Crédito, nele são ofertados conteúdos para o desenvolvimento e formação de colaboradores, associados, conselheiros e coordenadores de núcleo. Também são abordados conteúdos sobre o funcionamento das sociedades cooperativas, especialmente as cooperativas de crédito integrantes do Sicredi. Para difundir esses conhecimentos, foram planejados dois percursos de aprendizagem, com conteúdos organizados por Rotas temáticas: Percurso 1 - Contribuindo para 0 crescimento coletivo, Percurso 2 - compartilhando decisões e resultados e Percurso 3 - Administrando e Fiscalizando o Empreendimento Coletivo. 0 programa crescer é realizado anualmente para cada agência de forma presencial, reúne em cada edição associados e colaboradores que ainda não participaram das edições anteriores. O número de participantes varia de 15 a 20 associados convidados a participar do programa.

Essas coletas de dados realizadas produziram informações importantes sobre quais práticas de gestão do conhecimento a cooperativa desenvolve com seus colaboradores. Observou-se que algumas práticas são necessários investimentos financeiros, investimento em novas tecnologias, materiais impressos, palestrantes, ambiente para a execução. Por outro lado, temos outras que ocorrem no dia-a-dia sem que seja preciso muito esforço da organização para que ocorra.

Dessa forma a cooperativa pode se utilizar de práticas simples, mas que geram e proporcionam grandes resultados tanto para o crescimento do profissional que está trabalhando na equipe, como para a agência ou cooperativa que irá otimizar suas vantagens competitivas em relação aos seus concorrentes e ao mercado. Essas práticas sendo usadas de forma a adequá-las aos objetivos estratégicos da instituição no dia-a-dia de trabalho dos colaboradores vai fazer com que a criação, transferência e armazenamento de conhecimento sejam algo rotineiro dentro da cooperativa.

Após a identificação das práticas aplicou-se o espiral do conhecimento para classificar em qual fase cada prática se encaixa (Quadro 2).

Quadro 2: Classificação das Práticas no Espiral do Conhecimento

\begin{tabular}{|l|l|l|}
\hline & Conhecimento Tácito & Conhecimento Explícito \\
\hline $\begin{array}{l}\text { Conhec. } \\
\text { Tácito }\end{array}$ & Socialização & Externalização \\
\hline
\end{tabular}




\begin{tabular}{|c|c|c|}
\hline & $\begin{array}{l}\text { Reuniões internas } \\
\text { Palestras }\end{array}$ & 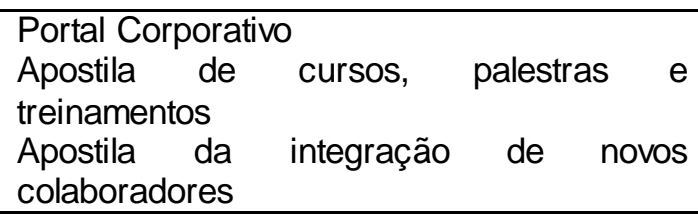 \\
\hline $\begin{array}{l}\text { Conhec. } \\
\text { Explícito }\end{array}$ & \begin{tabular}{l}
\multicolumn{1}{c}{ Internalização } \\
Estatuto social \\
Biblioteca interna \\
Treinamentos/capacitações \\
Cursos \\
Integração de novos colaboradores \\
Programa crescer \\
Murais
\end{tabular} & $\begin{array}{l}\text { Combinação } \\
\text { Auxílio Educação }\end{array}$ \\
\hline
\end{tabular}

Fonte: Autoria própria (2018)

O Quadro 2 demonstrou que se pode ter uma prática que engloba mais de uma etapa do espiral do conhecimento, pois uma prática ao mesmo tempo que transforma um conhecimento tácito em explícito também pode ser usado de forma a fazer o processo contrário, o que vai defini-lo será a forma de como ele é gerenciado ou aplicado aos colaboradores.

Davenport e Prusak (2003), ressaltam que é imprescindível que a organização gerencie o conhecimento que é transferido dentro dela entre os seus funcionários, pois assim é muito maior suas chances de alcançar o sucesso. Nesse sentido aplicou-se o espiral do conhecimento nas práticas de gestão da cooperativa, o que resultou em uma ampla visão de em qual fase de transferência do conhecimento está sendo mais aplicado o investimento e tempo de ensino e aprendizagem.

Observou-se que na fase de socialização é preciso ter pessoas altamente preparadas para transmitirem de forma esclarecedora e objetiva aos demais colaboradores o que a cooperativa quer que eles e absorvam e saibam, além de terem por responsabilidade de incentivarem a transferência de novas ideias, informações, sugestões de melhorias e experiências vividas entre a equipe.

No modo de internalização destaca-se a importância da interpretação dos conhecimentos explícitos encontrados nos livros, materiais impressos, normas, manuais e demais documentos da cooperativa.

Durante a externalização ocorre a transferência de conhecimento tácito em explícito, o indivíduo transfere seus conhecimentos para algo que seja de fácil interpretação do receptor.

Já no modo de combinação ocorre a junção de diferentes conhecimentos explícitos, onde observa-se que através de conhecimentos já explícitos os colaboradores conseguem gerar novos conhecimentos e desenvolve-los em seu ambiente de trabalho.

Em um segundo momento houve a aplicação dos instrumentos aos colaboradores para obter a percepção deles em relação essas práticas já citadas.

Dentre as 11 pessoas que trabalham na agência sul de Dois Vizinhos, cinco são do gênero feminino e seis do gênero masculino. A idade dos colaboradores do gênero feminino é entre 25 até 34 e entre o gênero masculino fica entre 22 até 35 . Já o tempo de serviço dos colaboradores na cooperativa varia entre 10 meses a 15 anos. No instrumento de pesquisa utilizado foi destacado o grau de escolaridade dos colaboradores da agência, e observou-se que três pessoas estão cursando o ensino superior, outras três pessoas concluíram o ensino superior e os outros cinco colaboradores está cursando uma pósgraduação, o que demonstrou o interesse dos indivíduos em agregar conhecimentos e continuarem a sua especialização.

Conforme idade dos colaboradores percebeu-se que se tem um alto grau de maturidade entres eles. Nos últimos três anos, a agência apresentou os seguintes graus de rotatividade: em 2015 o percentual foi de $16,67 \%$ o que significou que houve dois 
desligamentos durante o ano, em 2016 o percentual fechou em 8,33\% mostrando que houve apenas um desligamento naquele período e em 2017 o percentual se manteve em $8,3 \%$.

Após a aplicação dos questionários aos colaboradores da agência Sul de Dois Vizinhos do Sicredi Iguaçú PR/SC/SP, apresentou-se os resultados obtidos no Quadro 3.

Quadro 3: Percepção dos colaboradores em relação as práticas de gestão do conhecimento

\begin{tabular}{|c|c|c|c|c|c|c|c|c|}
\hline \multirow[t]{2}{*}{ PRÁTICAS } & \multicolumn{2}{|c|}{ JÁ USOU } & \multicolumn{3}{|c|}{$\begin{array}{c}\text { QUAL A } \\
\text { FREQUÊNCIA }\end{array}$} & \multicolumn{3}{|c|}{$\begin{array}{c}\text { GRAU DE } \\
\text { IMPORTÂNCIA }\end{array}$} \\
\hline & $\begin{array}{l}\sum \\
\stackrel{\Sigma}{\circ} \\
0^{\circ}\end{array}$ & 足 & 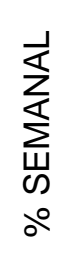 & 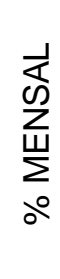 & 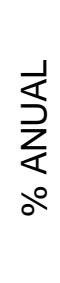 & 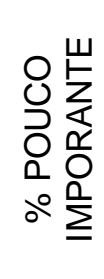 & 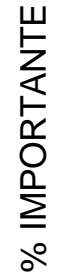 & 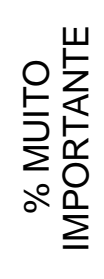 \\
\hline 1- Reuniões Internas & 100 & & 73 & 27 & & & & 100 \\
\hline 2- Mensuração dos Resultados & 100 & & & 82 & 18 & & & 100 \\
\hline 3- Estatuto Social & 100 & & & 27 & 73 & & 36 & 63,63 \\
\hline 4- Treinamentos e capacitações & 100 & & & 27 & 73 & & 9,1 & 90,9 \\
\hline 5- Cursos e Palestras & 100 & & & 18 & 82 & & 45 & 54,54 \\
\hline 6- Integração de novos colab. & 72,7 & 27 & & & 73 & & 27 & 72,28 \\
\hline 7- Auxílio Educação & 54,5 & 45 & & 54 & & 9,1 & & 90,9 \\
\hline 8- Biblioteca Interna & 81,8 & 18 & & 82 & & 27,27 & 27 & 45,46 \\
\hline 9- Portal Colaborativo & 100 & & 82 & 18 & & & 18 & 81,81 \\
\hline 10- Comunicação/e-mails/murais & 100 & & 100 & & & & & 100 \\
\hline 11- Programa Crescer & 81,8 & 18 & & & 82 & & 36 & 63,63 \\
\hline
\end{tabular}

Fonte: Autoria própria (2018)

Mesmo que todos os colaboradores da instituição tenham a sua disposição as 11 práticas mais utilizadas pela cooperativa, o Quadro 3 demonstrou que em algumas práticas não se obteve $100 \%$ de uso. Ao compararmos o tempo de empresa dos colaboradores com o uso das práticas de gestão do conhecimento que a cooperativa realiza percebeu-se que algumas práticas foram criadas mais recentemente, então os indivíduos que já estão á mais tempo na empresa não tiveram a oportunidade de realizá- 
las, por exemplo, a integração de novos colaboradores, a qual é realizada no momento em que colaborador inicia na cooperativa.

Nos itens 6 e 7 do Quadro 3, no que se refere ao grau de frequência de uso das atividades, não atingiu $100 \%$, pois como teve pessoas que não fizeram uso dessa prática automaticamente eles não responderam sobre a frequência. No entanto, esses indivíduos deram a sua opinião no que se referiu a importância dessa prática para a cooperativa e seus colaboradores. No item 8, pode-se perceber que, no que se referiu ao grau de importância a maioria considerou a prática pouco importante ou apenas importante, mesmo que já fizeram uso dessa prática.

Pode-se observar que o resultado geral da pesquisa no quesito "já usou" se concentrou na opção "sim", apresentando que as práticas de gestão do conhecimento que a cooperativa aderiu está tendo resultados positivos.

No Quadro 3, ficou evidente que no que se refere ao grau de frequência de utilização de cada prática apresentada, a maior utilização ocorre mensalmente e anualmente, isso é devido o fato de que a cooperativa desenvolve estratégias de gestão anualmente, então todos os anos se tem novos cursos, novas estratégias de mercado, apresentação de resultados e definir metas.

No grau de importância das atividades, de acordo com o que demonstrou o Quadro 3, identificou-se um elevado grau de consenso sobre o valor de cada prática, o que validou a boa forma da cooperativa trabalhar as práticas juntos com os seus colaboradores.

Durante a realização dos instrumentos de pesquisa com os colaboradores da agência sul de Dois Vizinhos, solicitou-se que os mesmos apontassem pontos positivos e sugestões de melhorias em relação as práticas de gestão do conhecimento da Sicredi Iguaçú $\mathrm{PR} / \mathrm{SC} / \mathrm{SP}$, para que assim a pesquisa conseguisse ter uma percepção da visão dos colaboradores. Após a leitura de todos os pontos levantados pelos colaboradores, percebeu-se que todos apresentaram sua visão perante cada atividade selecionada. Em seguida evidenciou-se algumas respostas obtidas através dos instrumentos de pesquisa.

Destacou-se que a prática de reuniões interna deixa a equipe mais focada, e alinhada para as suas atividades, deixa todos os colaboradores a par dos assuntos internos da cooperativa, se tem a oportunidade de expor suas ideias, sugestões de melhorias e ocorre também a troca de experiência.

Durante a mensuração dos resultados que ocorre anualmente com a superintendência da cooperativa ou mensalmente com a gerência da agência, todos destacaram que com essa prática conseguem verificar o andamento e desempenho da equipe, ocorrem feedbacks sobre a agência e obtêm uma ampla visão da importância do trabalho desenvolvido pela equipe naquele período.

Outro ponto destacado pelos colaboradores é a importância dos treinamentos e capacitações, pois contribuem para o crescimento profissional, agregam valor aos seus currículos, e aprimoram seus conhecimentos sobre o assunto estudado. Uma sugestão de melhorias citadas por alguns foi a do aumento do número de vagas oferecidas para os treinamentos presenciais, a participação de mais áreas e também sua execução com mais frequência.

Com relação ao item comunicação/e-mail/murais, observou-se que o ponto mais evidenciado pelos indivíduos é a agilidade, praticidade, e segurança das informações repassadas, essas ferramentas são muito eficientes para o desenvolvimento das atividades que ocorrem dentro da agência.

\section{Conclusão}

O mercado financeiro e empresarial está cada vez mais competitivo, e nesse cenário as empresas precisam estar sempre em adaptação e desenvolvimento, sempre 
investindo em inovação e estratégias de mercado. Para que a organização consiga passar por essa contínua transformação, é necessário que elas invistam em forma de gestão do conhecimento voltada para toda a empresa, tanto para os seus funcionários, clientes, fornecedores e diretoria, pois assim a empresa vai valorizar e gerir de forma mais eficiente o conhecimento gerado, compartilhado e armazenado pelos indivíduos.

Este artigo teve como objetivo avaliar as práticas do espiral do conhecimento aplicadas em uma cooperativa de crédito e investimento do sudoeste do Paraná, mostrando a percepção de seus colaboradores em relação a essas práticas.

Utilizou-se pesquisa em site, documentos e entrevista com o setor de recursos humanos e sociais, verificou-se que a cooperativa tem práticas de GC eficientes e que conseguem atingir um grande número de indivíduos em um curto período de tempo, pelo fato de investirem em práticas que utilizam a forma online. Aplicou-se o espiral do conhecimento para a classificação das atividades desenvolvidas pela cooperativa. Podese ter uma ampla visão de como estão distribuídas as práticas de GC nas etapas do espiral, o que evidenciou que as práticas estão bem distribuídas.

Em um segundo momento aplicou-se dois instrumentos de pesquisas aos colaboradores para obter-se a sua percepção em relação aos métodos de gestão do conhecimento que a cooperativa utiliza. Observou-se com os resultados desses instrumentos que as práticas são realmente vistas como atrativas pelos colaboradores e os mesmos valorizam o interesse da cooperativa em motivar a participação e crescimento profissional de todos que estão envolvidos com a instituição.

Sugere-se que para as próximas pesquisas a serem realizadas na Sicredi Iguaçú PR/SC/SP o objetivo de analisar a gestão do conhecimento voltada para as práticas que a cooperativa desempenha com os seus associados.

Diante dos resultados obtidos pela pesquisa, constata-se que a Sicredi Iguaçú PR/SC/SP aplica várias práticas de GC de fácil acesso para os seus colaboradores, e os mesmos estão satisfeitos com a forma de como a cooperativa desenvolve essas atividades, o que disponibiliza para a organização uma vantagem competitiva.

\section{Referências}

BEHR, R. R.; NASCIMENTO, S. P. A gestão do conhecimento como técnica de controle: uma abordagem crítica da conversão do conhecimento tácito em explícito. Cadernosebape.br. [online], v. 6, n. 1, p. 1-11, 2008.

BEAL, J. R. S.; CARLETTO, B.; FERREIRA, C. L. As sete dimensões da gestão do conhecimento da empresa Pão de Queijo e Cia. In: Congresso Internacional de Administração, 2008, Ponta Grossa. Anais... Ponta Grossa: UFPG (Universidade Federal de Ponta Grossa), 2008.

DAVENPORT, T. H.; PRUSAK, L. Conhecimento empresarial: como as organizações gerenciam o seu capital intelectual. 15. reimpressão. Rio de Janeiro: Elsevier, 2003.

FIALHO, F. A. P.; PONCHIROLLI, O. Gestão estratégica do conhecimento como parte da estratégia empresarial. v. 17, n. 1, p. 1-12, 2005.

GIL, A. C. Como elaborar projetos de pesquisa. Ed. 12. São Paulo: Atlas. 2009.

INAZAWA, F. K. O papel da cultura organizacional e da aprendizagem para o sucesso da gestão do conhecimento. portaldeperiodicos.eci.ufmg.br [online]. 2009. v. 14. n. 3, p. 206-220. 
MONTANARI, R. L. Influência de trabalhar em grupos nos processos de construção do conhecimento organizacional. Revista Gestão Industrial. 2009. v.05. n. 1. P. 194-210.

NONAKA, I.; TAKEUCHI, H. Criação do conhecimento na empresa: como as empresas japonesas geram a dinâmica da inovação. Rio de Janeiro: Campus, 1997.

PEREIRA, A.D.S. A gestão do conhecimento como mecanismo de desenvolvimento de capacidades dinâmicas nas organizações. In: Congresso Internacional de Administração, 2016, Natal - RN. Anais... Natal : UFPG: Universidade Federal de Ponta Grossa, 2015. p. $1-12$.

SILVA, S. L.; ROZENFELD, H. Modelo de avaliação da gestão do conhecimento no processo de desenvolvimento do produto: aplicação em um estudo de caso. Revista produção de Florianópolis. Florianópolis, abril/jun/jul. v. 13. n. 2. p. 1-15, 2003.

SOUZA, J. M. Tendências Contemporâneas de Gestão: técnicas de gestão para MPE'S Brasileiras. São Paulo: PC, 2003.

TERRA, J. C.; KRUGLIANSKAS, I. Gestão do conhecimento em pequenas e médias empresas. Rio de Janeiro: Campus, 2003.

YIN, R. K. Estudo de Caso: planejamento e métodos. 2. ed. Porto Alegre: Bookman, 2001. 